\title{
O PROEJA NA EDUCAÇÃO DO CAMPO: UMA ANÁLISE CURRICULAR DA DISCIPLINA DE EDUCAÇÃO FÍSICA
}

\section{THE PROEJA IN RURAL EDUCATION: A CURRICULAR ANALYSIS OF THE DISCIPLINE OF PHYSICAL EDUCATION}

\author{
Sâmmya Faria Adona ${ }^{1}$
}

\begin{abstract}
RESUMO: O presente trabalho teve como objeto de pesquisa a análise da inclusão da disciplina de educação física na matriz curricular do Programa Nacional de Integração da Educação Profissional com a Educação Básica na Modalidade de Educação de Jovens e Adultos - PROEJA - em uma escola da zona rural de Boa Vista - Roraima. Os objetivos da pesquisa foram: conceituar as bases que fundamentam o currículo da educação física escolar na perspectiva da educação do campo e dos alunos do PROEJA; compreender de que maneira a disciplina de educação física pode se tornar significativa para o aluno do PROEJA dentro da realidade do campo; e relatar sobre a aplicabilidade da inclusão da disciplina de educação física no currículo do PROEJA da referida instituição. Quanto aos procedimentos metodológicos, utilizou-se a etnometodologia como método, por se considerar mais adequada para avaliar uma situação em determinado momento que ocorre em um grupo social; evidenciando quais as influências derivadas de experiências práticas e teóricas. Esse processo metodológico é de natureza qualitativa, constituído por uma pesquisa documental, bibliográfica e de campo, onde foram realizadas entrevistas com gestores da instituição de ensino e a aplicação de questionários com os alunos do PROEJA. Os resultados da pesquisa apresentam especificidades da compreensão dos alunos e gestores em relação à educação física, seus conteúdos e sua prática no âmbito escolar.
\end{abstract}

Palavras-chave: Educação do Campo; PROEJA; Educação Física; Etnometodologia.

\begin{abstract}
The present paper had as its research object the analysis of the inclusion of Physical Education in the curricular matrix of the Integration of Professional Educational National Program with the Basic Education for Young and Adults Education Modality (PROEJA) in a school in the rural area of Boa Vista - Roraima. The research goals were: to conceptualize the basis which grounds the school Physical Education curriculum on the rural education and PROEJA's students perception; to comprehend in which way Physical Education may become significant to the PROEJA's student within the rural reality; and to report about the applicability of the inclusion of Physical Education in PROEJA's curriculum of the referred institution. Regarding the methodological procedures, it was used an ethnometodology as a method, for it was regarded as most appropriate to avail the situation which happens in a social group, in a determined moment, evidencing which were the influences derived from theoretical and practical experiences. This methodological procedure is of qualitative nature, constituted by a documentary, bibliographic and field research, in which were applied interviews with principals of the educational institution and questionnaires with PROEJA's students of the institution studied. The theoretical considerations present specificities for the students and principals comprehension of Physical Education, its subjects and practice on school's scope.
\end{abstract}

Keywords: Rural education; PROEJA, Physical Education. Ethnomethodology.

\footnotetext{
${ }^{1}$ Mestre em Educação. Especialista em Planejamento, Implantação e Gestão em Educação EAD, Especialista em Docência Superior, Especialista em Assessoria de Comunicação e Novas Tecnologias. Licenciada em Pedagogia, Educação Física e graduada em Comunicação Social - Jornalismo.

Revista Labor Fortaleza/CE, jan/jul 2017 Vol. 01, n 17, p. 13-26 ISSN 1983-5000
} 


\section{INTRODUÇÃ̃O}

O presente artigo derivou da inquietação ao ponderarmos a relação prática existente entre os propósitos da educação do campo e o ensino médio agregado à formação profissional (curso técnico em agropecuária), especificamente na modalidade de educação de jovens e adultos.

Para tanto, analisamos duas projeções históricas que delimitam o teor do enfoque: a educação do campo e a disciplina de educação física no âmbito escolar. Essas duas perspectivas são vinculadas ao Programa Nacional de Integração da Educação Profissional PROEJA da Escola Agrotécnica da Universidade Federal de Roraima - EAGRO/UFRR.

Nem sempre a educação seguiu as diretrizes impostas nas legislações vigentes e ainda nos dias atuais percebemos falhas no processo do cumprimento efetivo. Por isso, cabe a preocupação: O currículo levado ao homem do campo é adequado ao que ele vivencia? A realidade do homem do campo é retratada no currículo? As diretrizes impostas pela legislação são efetivadas na prática?

Para o delineamento das respostas de tais indagações, construímos um aporte teórico sobre $\mathrm{O}$ Currículo e suas Perspectivas apresentando uma abordagem sobre $\mathrm{O}$ Currículo da Educação do Campo, O Currículo da Educação Física, O currículo do PROEJA em normativas e O Currículo do PROEJA da referida instituição que conta com o posicionamento de autores como Boiago e Oliveira (2012), Souza Filho (2009), Ciavatta (2005) e outros.

O método da análise do processo utilizado desta pesquisa foi a etnometodologia, condizente com o objeto de estudo, focando a relação do grupo social a ser pesquisado e os processos do meio. Para a legitimidade do aporte teórico, abordamos as diretrizes de Garfinkel (2006) onde o autor traça os caminhos da Etnometodologia.

Para explanar sobre esse aspecto em foco, um questionário foi aplicado com os alunos das duas turmas do PROEJA da EAGRO/UFRR e com os gestores educacionais diretamente envolvidos. Entendemos que por meio desse procedimento, tornou-se possível retratar a realidade dos sujeitos em questão e o posicionamento da Instituição diante de suas propostas curriculares.

Ao final da pesquisa chegamos às considerações que a disciplina de educação física deve ser incluída na matriz curricular do Programa Nacional de Integração da Educação Profissional com a Educação Básica na Modalidade de Educação de Jovens e Adultos - 
PROEJA - da Escola Agrotécnica da Universidade Federal de Roraima - EAGRO/UFRR; enfatizando a necessidade de ampliação da abordagem deste debate na construção da prática de propostas educacionais condizentes com uma educação eficaz.

\section{O CURRÍCULO E SUAS PERSPECTIVAS}

O currículo é algo que está no cotidiano da escola, de forma expressiva e oculta. De forma expressiva, por meio da missão e valores da escola, e diretamente no PPP-Projeto Político Pedagógico; e de forma oculta, por meio dos agentes da educação, que às vezes, mesmo sem perceber, afetam o andamento do processo escolar em sua forma de pensar e agir. Segundo Silva:

O currículo oculto nas escolas serve para reforçar as regras que cercam a natureza e o uso dos conflitos. E estabelece uma rede de suposições que visa determinar regras sobre a conduta dos estudantes. (2003, p. 78)

Sabemos que além do professor que lida com o aluno diretamente em sala de aula, outros agentes da educação colaboram com o currículo. Diante disso, para esclarecimento, precisamos conceituar o que é currículo. Para Veiga Neto:

Currículo é uma construção social do conhecimento, pressupondo a sistematização dos meios para que esta construção se efetive; a transmissão dos conhecimentos historicamente produzidos e as formas de assimilá-los, portanto, produção, transmissão e assimilação são processos que compõem uma metodologia de construção coletiva do conhecimento escolar, ou seja, o currículo propriamente dito. (2002, p.7)

Logo, para que o currículo tenha alcance concreto, é preciso estar inserido dentro da realidade do aluno. Não basta apenas o conteúdo pedagógico propor isso, é preciso a efetivação na prática.

\section{O Currículo da Educação do Campo}

Mesmo as escolas do campo tendo seus arranjos de funcionamento próprios, a educação do campo ainda não se constitui em uma modalidade de ensino, como no caso da educação indígena. Mas grandes mudanças foram e estão sendo pleiteadas nos dias atuais, como as Diretrizes Operacionais para a Educação Básica das Escolas do Campo, do Parecer 
n $36 / 2001$ da relatora Edla de Araújo Lira Soares, e instituída pela Resolução CNE/CEB nº 1 , de 3 de abril de 2002.

A concepção de Educação do Campo proposta pelas Diretrizes Operacionais para Educação Básica nas Escolas do Campo (2001) vai além da concepção de educação rural que se tinha, a saber, uma educação que considerava apenas a dimensão econômica. A nova concepção abrange a emancipação humana, o atendimento as especificidades do campo, levando em consideração aspectos da cultura campesina, da identidade dos sujeitos em questão, das relações sócio-ambientais e também das organizações políticas. (BOIAGO e OLIVEIRA, 2012, p. 5)

Em 2008, a Resolução no 2 do CNE/CEB estabeleceu diretrizes complementares, normas e princípios para o desenvolvimento de políticas públicas de atendimento da Educação Básica do Campo. Em seu Art. $1^{\circ}$ :

Art. $1^{\circ}$ A Educação do Campo compreende a Educação Básica em suas etapas de Educação Infantil, Ensino Fundamental, Ensino Médio e Educação Profissional Técnica de nível médio integrada com o Ensino Médio e destina-se ao atendimento às populações rurais em suas mais variadas formas de produção da vida agricultores familiares, extrativistas, pescadores artesanais, ribeirinhos, assentados e acampados da Reforma Agrária, quilombolas, caiçaras, indígenas e outros. (MEC, 2008)

Essas Diretrizes, aprovadas pelo Conselho Nacional de Educação, refletem a preocupação na organização da educação do campo e as características específicas de cada região. Em 2013, com a publicação das Novas Diretrizes Curriculares da Educação Básica, também tratou das Diretrizes Operacionais para a Educação Básica nas escolas do campo:

(...) Ao lado disso, observa-se que algumas Cartas estaduais trazem referências mais específicas à educação rural, determinando, na oferta da educação básica para a população do campo, adaptações concretas inerentes às características e peculiaridades desta. É o que ocorre nos Estados de Alagoas, Bahia, Ceará, Maranhão, Sergipe e Tocantins, que prescrevem sejam os calendários escolares da zona rural adequados aos calendários agrícolas e às manifestações relevantes da cultura regional.

(...) Essa orientação também é identificada nos Estados do Pará, Paraíba, Roraima, Santa Catarina, Sergipe e Tocantins, que determinam a fixação de currículos para a zona rural consentâneos com as especificidades culturais da população escolar. (MEC, 2013, p. 274)

O mesmo documento, ao se tratar de Roraima revela:

A Constituição de Roraima, no art. 149, II, diz que os conteúdos mínimos para o ensino fundamental e médio serão fixados de maneira a assegurar, além da formação básica, currículos adaptados aos meios urbanos e rural, visando ao desenvolvimento da capacidade de análise e reflexão crítica sobre a realidade. (MEC, 2013, p. 275) 
Logo, ao se pensar em um currículo para uma escola do campo, é preciso pensar na realidade dos sujeitos e a contribuição das disciplinas para a formação básica e profissional.

\section{O Currículo da disciplina de Educação Física}

Diante de tantos benefícios já concretizados pela educação física é indiscutível sua atuação no âmbito escolar. A Lei nº 9394, de 20 de dezembro de 1996, que estabelece a Lei de Diretrizes e Bases da Educação Nacional traz em seu texto a obrigatoriedade da educação física escolar como currículo obrigatório em todo o ensino básico. E determinada que ela seja facultativa para os alunos que:

I. que cumpra jornada de trabalho igual ou superior a seis horas;

II. maior de trinta anos de idade;

III. que estiver prestando serviço militar inicial ou que, em situação similar, estiver obrigado à prática da educação física;

IV. amparado pelo Decreto-Lei no 1.044, de 21 de outubro de 1969;

V. (VETADO);

VI. que tenha prole.

Em 2012 novas Diretrizes Curriculares Nacionais foram lançadas. Estas são fixadas pelo Conselho Nacional de Educação (CNE) com o proposito de orientar as políticas educacionais e implementar propostas curriculares em todo o Brasil. Em cooperação com as DCN's estão os PCN's - Parâmetros Curriculares Nacionais - que são referenciais de qualidade elaboradas pelo Governo Federal e oferecem embasamento teórico para nortear as escolas na execução do currículo.

Estes Parâmetros propagam os princípios da base curricular e orientam os profissionais ao propor abordagens e metodologias. Os PCN's abarcam desde a organização dos conteúdos de cada disciplina quanto à forma de abordagem, auxiliando os docentes da área numa perspectiva de conduta positiva para múltiplas situações.

É importante salientar que, nem as Referenciais Curriculares Nacionais da Educação Profissional e nem as Diretrizes Curriculares Nacionais para a Educação Profissional de Nível Técnico orientam sobre as disciplinas da educação básica, como a educação física, e sim sobre as disciplinas de cada curso da área técnica.

Mas alguns autores revelam a importância da disciplina em nível técnico, é o caso de Souza Filho (2009 apud GUIMARÃES; VALDEZ). O autor esclarece sobre a educação física no PROEJA: 
[...] para a Educação Física consolidar-se como componente curricular no PROEJA e colaborar para que o sujeito EJA se reconheça como ser pensante e atuante na sociedade, as aulas deveriam ser desenvolvidas a partir da perspectiva dos alunos, das suas representações, de suas ideias e dos seus interesses de modo que esses aspectos promovessem uma ação pedagógica afirmativa, tanto no processo de ensino orientado quanto no processo de aprendizagem participante (2009, p. 119-120).

O próprio autor ainda acrescenta em suas falas sobre a aplicabilidade da educação física para jovens e adultos, muito além de uma disciplina, um meio de inserção social.

[...] seria relevante para a Educação Física estar presente no processo de inclusão sócio-educacional e cultural dos alunos da EJA e, nesse processo, analisar, discutir e valorizar a história de vida desses sujeitos, as marcas tatuadas na sua corporeidade, os seus valores, as suas concepções políticoideológicas e econômicas, a sua dimensão cultural e a sua percepção de mundo (SOUZA FILHO, 2009, p. 120).

Outra fonte que orienta o caminho da educação física no PROEJA, é a Proposta Curricular de Educação Física para a EJA, que foi criada em 2002 pela Secretaria de Educação Fundamental com base na Resolução no 01/2000 (Estabelece as Diretrizes Curriculares Nacionais para a Educação e Jovens e Adultos) e no Parecer CNE/CEB n ${ }^{\circ}$ 11/2000 (Diretrizes Curriculares Nacionais para a Educação de Jovens e Adultos). A Proposta é composta por dois volumes, que se dividem em disciplinas e áreas e estabelece as competências, com o objetivo de:

[...] promover a integração e a inserção de todos os alunos nas práticas corporais; valorizar, apreciar e desfrutar dos benefícios advindos da cultura corporal de movimento; perceber e compreender o papel do esporte na sociedade contemporânea; usufruir do tempo livre de lazer, resgatando o prazer enquanto aspecto fundamental para a saúde e melhoria da qualidade de vida; valorizar, por meio do conhecimento sobre o corpo, a formação de hábitos de cuidado pessoal; compreender e ser capaz de analisar criticamente valores sociais como padrões de beleza, relações entre os sexos e preconceitos (BRASIL, 2002, p. 205-206).

Atualmente, almeja-se que as aulas de Educação Física possam oportunizar o aluno a vivenciar a diversidade das práticas corporais por meio de conhecimentos que enfatizam a cultura corporal de movimento, considerando a evolução individual de cada educando.

\section{O Currículo do PROEJA}

O currículo escolar constitui a organização de conteúdos diante das relações que acontecem entre os agentes da educação. Para integrar o currículo básico com a formação profissional, é preciso coerência nos processos de ensino-aprendizagem. Ao se falar no currículo que integra a formação básica com a formação para o trabalho, tem-se: 
Como formação humana, o que se busca é garantir ao adolescente, ao jovem e ao adulto trabalhador o direito a uma formação completa para a leitura do mundo e para a atuação como cidadão pertencente a um país, integrado dignamente à sua sociedade política. Formação que, neste sentido, supõe a compreensão das relações sociais subjacentes a todos os fenômenos (CIAVATTA, 2005, p. 85).

Os cursos do PROEJA podem ser oferecidos da seguinte forma, de acordo com a construção do projeto pedagógico integrado:

1- Educação profissional técnica integrada ao ensino médio na modalidade de educação de jovens e adultos.

2- Educação profissional técnica concomitante ao ensino médio na modalidade de educação de jovens e adultos.

3- Formação inicial e continuada ou qualificação profissional integrada ao ensino fundamental na modalidade de educação de jovens e adultos.

4- Formação inicial e continuada ou qualificação profissional concomitante ao ensino fundamental na modalidade de educação de jovens e adultos.

5- Formação inicial e continuada ou qualificação profissional integrada ao ensino médio na modalidade de educação de jovens e adultos.

6- Formação inicial e continuada ou qualificação profissional concomitante ao ensino médio na modalidade de educação de jovens e adultos. (BRASIL, Decreto 5.840/2006)

O Decreto $\mathrm{n}^{\circ}$ 5.840, de 13 de julho de 2006 que institui, no âmbito federal, o Programa Nacional de Integração da Educação Profissional com a Educação Básica na Modalidade de Educação de Jovens e Adultos - PROEJA, estabelece em seu Art. $3^{\circ}$ e Art. $4^{\circ}$ que:

Art. $3^{\circ}$ Os cursos do PROEJA, destinados à formação inicial e continuada de trabalhadores, deverão contar com carga horária mínima de mil e quatrocentas horas, assegurando-se cumulativamente:

I - a destinação de, no mínimo, mil e duzentas horas para formação geral; e

II - a destinação de, no mínimo, duzentas horas para a formação profissional.

Art. $4^{\circ}$ Os cursos de educação profissional técnica de nível médio do PROEJA deverão contar com carga horária mínima de duas mil e quatrocentas horas, assegurando-se cumulativamente:

I - a destinação de, no mínimo, mil e duzentas horas para a formação geral;

II - a carga horária mínima estabelecida para a respectiva habilitação profissional técnica; e

III - a observância às diretrizes curriculares nacionais e demais atos normativos do Conselho Nacional de Educação para a educação profissional técnica de nível médio, para o ensino fundamental, para o ensino médio e para a educação de jovens e adultos. (BRASIL, 2006)

\section{Segundo o mesmo decreto:}

$\S 3^{\circ}$ O PROEJA poderá ser adotado pelas instituições públicas dos sistemas de ensino estaduais e municipais e pelas entidades privadas nacionais de serviço social, aprendizagem e formação profissional vinculadas ao sistema sindical. (BRASIL, Decreto 5840/2006, art. $1^{\circ}$ ) 
Nas Diretrizes Curriculares Nacionais para a Educação Profissional Técnica de Nível Médio, criada pelo parecer CNE/CEB No 11/2012 consta que o Decreto 5.154/2004 integrou novamente o ensino médio à educação profissional técnica de nível médio, fazendo com que a CNE - Conselho Nacional de Educação reformulasse as Diretrizes Curriculares Nacionais para o Ensino Médio e as Diretrizes Curriculares Nacionais para a Educação Profissional Técnica de Nível Médio, por meio da Resolução CNE/CEB no 1/2005, com fundamento no Parecer CNE/CEB nº 39/2004. No texto, as Diretrizes enfocam que:

\begin{abstract}
Espera-se que o mundo do trabalho avance na direção de relações trabalhistas mais justas. Isso implica numa maior participação dos trabalhadores nos destinos e nos processos de trabalho. Para que isso aconteça é necessário que o trabalhador tenha conhecimento da tecnologia, da ciência e dos processos necessários em sua produção. A escola especializada ou voltada para a formação profissional deve atentar para essa necessidade.(BRASIL, 2013, p. 208)
\end{abstract}

Em 2008, a LDB teve uma Seção acrescida pela Lei n 11.741, a Seção IV-A, que demanda sobre a Educação Profissional Técnica de Nível Médio. Em seu paragrafo único é retratado que:

\footnotetext{
Parágrafo único. A educação profissional técnica de nível médio deverá observar: I - os objetivos e definições contidos nas diretrizes curriculares nacionais estabelecidas pelo Conselho Nacional de Educação;

II - as normas complementares dos respectivos sistemas de ensino;

III - as exigências de cada instituição de ensino, nos termos de seu projeto pedagógico. (BRASIL, 1996)
}

Assim, impossível pensar em educação com distanciamento da formação profissional do sujeito, essa formação intrínseca com a cultura, a econômica, a política e as questões sociais, fazendo com que o aluno, seja um cidadão atuante na sociedade.

\title{
O PROEJA na Escola Agrotécnica da UFRR - EAGRO
}

A Escola Agrotécnica da Universidade Federal de Roraima - EAGRO/UFRR possibilita a formação na educação profissional técnica integrada ao ensino médio na modalidade de educação de jovens e adultos. O curso técnico proposto é de Agropecuária, e foram organizados com base nas Resoluções CEB/CNE 3/98, que institui as diretrizes curriculares nacionais para o ensino médio, e CEB/CNE 6/12, que define as diretrizes curriculares nacionais para a educação profissional técnica de nível médio. 
Na modalidade PROEJA os alunos tem aulas durante os turnos matutino e vespertino, com o currículo de três (03) anos organizados em séries anuais e estágio obrigatório.

\begin{abstract}
(...) 360 horas para o ensino médio integrado e 240 horas para na Modalidade PROEJA e o tempo máximo para integralização da matriz curricular, incluindo o estágio, será de 05 (cinco) anos. Durante os três anos de duração são ofertadas todas as disciplinas necessárias para a base técnica e do ensino médio aos alunos. O curso busca promover a articulação entre os saberes que devem contemplar a formação geral desenvolvida pelo ensino médio articulado às necessidades e expectativas conceituais da formação profissional. Na Modalidade PROEJA, busca-se ainda, a valorização dos saberes adquiridos em espaços de educação não-formal. (Projeto Pedagógico do Curso Técnico em Agropecuária, atualizado em abril de 2013)
\end{abstract}

O Projeto Pedagógico da EAGRO/UFRR foi atualizado em abril de 2013 e dispõe sobre a matriz curricular do Curso Técnico em Agropecuária Integrado ao Ensino Médio na Modalidade de Educação de Jovens e Adultos (PROEJA) com uma parte comum, uma parte diversificada, uma parte da formação profissional e o núcleo completar referente ao estágio supervisionado. Esta matriz não adere a disciplina de educação física na grade curricular.

\title{
RESULTADOS E DISCUSSÕES
}

Para nos orientar sobre a metodologia, autores como Gerhardt e Silveira (2009) e Fonseca (2002) sustentam os processos e métodos abarcados durante a pesquisa de campo. Já especificamente no tópico sobre o método, Garfinkel (2006) descreve a importância da etnometodologia neste tipo de análise.

O tipo de pesquisa utilizado foi de natureza qualitativa, bibliográfica e documental, onde o enfoque etnográfico apresentou a etnometodologia como abordagem metodológica. Nas palavras de Garfinkel (2006), criador da pesquisa etnometodológica, tais estudos:

[...] tratam as atividades e circunstâncias práticas, e o raciocínio sociológico prático como se fossem temas de estudo empírico. Ao prestar a mesma atenção tanto às atividades banais da vida cotidiana, quanto aos acontecimentos extraordinários, vamos procurar apreendê-las como fenômenos de pleno direito. (GARFINKEL, 2006, p. 1)

Nessa linha, a etnometodologia analisa as crenças e os comportamentos do senso comum como componentes necessários para toda conduta socialmente organizada.

Assim, foi realizado um questionário aplicado com os alunos do PROEJA da EAGRO/UFRR e também uma entrevista com os gestores da referida instituição para que Revista Labor Fortaleza/CE, jan/jul 2017 Vol. 01, nº 17, p. 13-26 ISSN 1983-5000 
informações gerenciais ficassem evidentes no processo de análise. Considerando as respostas do questionário o que mais se destaca no entendimento dos alunos perante a disciplina de educação física são conteúdos esportivos, que gerem gasto energético para proporcionar uma melhor qualidade de vida.

Contudo, é importante lembrar que a educação física não é somente para atletas ou para a descoberta deles. A sua dimensão na formação humana é bem maior. Claro, que o esporte tem papel de ênfase na disciplina, mas como uma fonte de diversão, lazer e bem-estar, possibilitando o trabalho de concentração, raciocínio e disciplina nas tarefas propostas. Como acentua De Marco (1995):

Mais do que formar atletas, a educação física pode contribuir com o desenvolvimento pleno da pessoa, com a formação de uma consciência crítica, com o conceito de cidadania e com o próprio desenvolvimento da consciência corporal (DE MARCO, 1995, p. 33).

O que se percebe é que eles não vivenciaram a prática esportiva na escola, já que se trata de um público em que não cursou o ensino regular. Em virtude da ausência dessas práticas, procuram interligar o esporte aos momentos de lazer, de jogos, ressaltando sempre a preocupação com a qualidade vida. Muitas vezes esses quesitos podem ser proporcionados não somente pelo esporte, mas por atividades lúdicas que trazem a realidade social de cada um, valorizando a cultura corporal de movimento e deixando de lado a esportivização.

Embora um dos gestores acredite ser desnecessário a inclusão da disciplina de educação física no PROEJA, sob a legação que já praticam atividade física nas ações das disciplinas técnicas, as questões corporais não se baseiam apenas no gasto energético. Suas dimensões são ampliadas quando nos referimos aos aspectos conceituais, atitudinais e procedimentais que a educação física propõe de acordo com cada atividade. Essa atividade evidenciada pelo movimento corporal de cada sujeito, o fazendo repensar sobre como mesmo se vê e sua imagem corporal diante dos outros. Darido S.C. et al (2001), dispõe sobre isso quando se refere nas dimensões sobre os conteúdos:

Neste sentido, o papel da Educação Física ultrapassa o ensinar esporte, ginástica, dança, jogos, atividades rítmicas, expressivas e conhecimento sobre o próprio corpo para todos, em seus fundamentos e técnicas (dimensão procedimental), mas inclui também os seus valores subjacentes, ou seja, quais atitudes os alunos devem ter nas e para as atividades corporais (dimensão atitudinal). E, finalmente, busca garantir o direito do aluno de saber porque ele está realizando este ou aquele movimento, isto é, quais conceitos estão ligados àqueles procedimentos (dimensão conceitual). (DARIDO S.C. et al, 2001, p.21) 
Para que isso se efetive é preciso pensar sobre o público-alvo a quem a educação física se destina e que os conteúdos propostos se tornem significativos com o intuito da inserção desses alunos. No caso específico, são alunos que não puderam concluir o ensino médio regular e tiveram ao longo da trajetória escolar, interrupções no reconhecimento das mudanças corporais e cognições relativas a esse processo.

(...). Na história da EJA, encontraremos uma constante: partir dessas formas de
existência populares, dos limites de opressão e exclusão em que são forçados a ter
de fazer suas escolhas entre estudar ou sobreviver, articular o tempo rígido de escola
com o tempo imprevisível da sobrevivência. Essa sensibilidade para essa concretude
das formas de sobreviver e esses limites a suas escolhas merece ser aprendida pelo
sistema escolar se pretende ser mais público. Avançando nessas direções, o diálogo
entre EJA e sistema escolar poderá ser mutuamente fecundo. Um diálogo
eminentemente político, guiado por opções políticas, por garantias de direitos de
sujeitos concretos. Não por direitos abstratos de sujeitos abstratos (ARROYO, 2005,
p. 49)

Para um dos gestores, a disciplina de educação física não deveria ser incluída já que os alunos possuem uma grade curricular diminuída, onde outras disciplinas também tiveram redução da carga horária. Mas para o outro gestor, a disciplina deve ser incluída apenas com a reformulação de conteúdos, nos quais entre eles sugere: corporeidade (recomendação energética, hidratação, alimentação saudável, obesidade, anorexia); ergonomia; doenças; ginástica laboral; relaxamento; expressão corporal (imagem corporal)

Assim, diante das interpretações dos resultados obtidos e no embasamento teórico legitimado, entende-se que não é possível desassociar a educação física na formação do aluno como sujeito, esse, necessitando se reconhecer dentro da realidade que o cerca por meio de sua compreensão corpórea.

Contudo, ao enfatizar a inclusão, não deixamos de lado a preocupação com os instrumentos necessários para a integração com o currículo, agregando o aluno na cultural corporal de movimento e no exercício da cidadania e no sua condução crítica de sujeito, papel este do próprio ambiente escolar. Esses instrumentos referem-se aos conteúdos propostos pela instituição escolar, a carga horária destinada a esse meio e a metodologia empregada para tal.

Uma escola que assume por missão consolidar a capacidade e a vontade dos indivíduos de serem atores e ensinar a cada um a reconhecer no outro a mesma liberdade que em si mesmo, o mesmo direito à individualização e à defesa de interesses sociais e valores culturais, é uma escola de democracia,... (TOURAINE 1998, p.339). 
Nessa perspectiva, propomos como caminho para a organização do ensinoaprendizagem a flexibilidade do currículo, a interdisciplinaridade, as ponderações dos alunos e a reflexão sobre o contexto social e profissional.

\section{CONSIDERAÇÕES FINAIS}

Desde Platão é indiscutível que a escola é essencial na formação humana, não como um conjunto de salas e pessoas; mas como um lugar em que se aprende a ética e a moral pelos conteúdos escolares, pelas regras, pela burocracia, pelo currículo, pelos agentes educacionais, pela gestão, pela solidariedade, pelo afeto. Pois a escola é um lugar social, político, econômico e cultural.

Da infância a fase adulta a escola tem o compromisso com a formação humana e isso compreende muito mais que a mecanização de disciplinas em um rígido tempo para assimilação de saberes. Além de possibilitar a formação profissional, a escola deve instigar o sujeito a boas ações, de caráter, respeito ao próximo e legalidade de seus atos pela constituição, tornando-o um ser crítico e participativo na sociedade.

Ao refletir sobre a inclusão da disciplina de educação física na matriz curricular do Programa Nacional de Integração da Educação Profissional com a Educação Básica na Modalidade de Educação de Jovens e Adultos - PROEJA - da Escola Agrotécnica da Universidade Federal de Roraima -EAGRO, possibilita-se um olhar sobre os ensinoaprendizagem direcionado a formação do sujeito-aluno.

Nessa perspectiva pedagógica, há uma demanda de fatores intrínsecos e extrínsecos do processo educacional, como a relação de educação-trabalho, perfil dos alunos, opiniões de gestores, currículo do PROEJA, fundamentação legal sobre a educação do campo e a prática da educação física no ambiente escolar.

Nesse contexto, ao analisar o objeto em questão, outros fatores também foram evidenciados como o resgate da cidadania dos sujeitos em formação, o EJA como política educacional do governo, a profissionalização, e as desigualdades sociais resultantes da falta de políticas públicas para a área rural. Por isso é primordial que a escola discuta com seus agentes envolvidos sobre as problemáticas em evidência e retorne à sociedade soluções; e isso só será possível com diálogo, pesquisa e conhecimento.

Quando falamos em jovens e adultos que não cursaram o ensino regular, no caso em questão o ensino médio, abordamos aspectos peculiares de cada sujeito, em vivências histórias heterogêneas. Adicionamos aí, as condições educacionais nada satisfatórias para o público-alvo, o aluno do campo. 
Nessa dimensão, a inclusão da educação física como disciplina obrigatória deve favorecer a relação educação-homem-trabalho, colocando-o como sujeito cultural, histórico, político e econômico que é, e precisa se reconhecer como membro social.

Por isso, a instituição escolar inserida dentro dos parâmetros da educação do campo, deve elaborar o currículo em consonância com os anseios dos alunos diante da realidade que os cerca. Percebe-se assim a relevância que uma disciplina aponta em direção aos conteúdos proposto em harmonia com a concepção integral do ser humano; fundamentando um currículo efetivo de inclusão social, formação básica e capacitação profissional; construindo instrumentos pedagógicos enriquecedores para a melhoria do processo de ensino-aprendizagem.

Diante disso, a disciplina de educação física deve ser inserida na matriz curricular do Programa Nacional de Integração da Educação Profissional com a Educação Básica na Modalidade de Educação de Jovens e Adultos - PROEJA - da Escola Agrotécnica da Universidade Federal de Roraima - EAGRO/UFRR; fomentando ainda o estudo e as colaborações nessa área para que se tornem fonte de aprimoramento e qualidade na educação para o homem do campo, por isso propomos a continuidade dessa relevante pesquisa como forma de aprofundamento do trabalho apresentado.

\section{REFERÊNCIAS}

ARROYO, M. G. Educação de jovens - adultos: um campo de direitos e de responsabilidade pública. In: SOARES, L. (Org.). Diálogos na educação de jovens e adultos. São Paulo: Autêntica, 2005.

BRASIL. Diretrizes Operacionais para a Educação Básica nas Escolas do Campo. Brasília, MEC/SECAD, 2002.

BRASIL, Lei de Diretrizes e Bases. Lei no 9.394/96, de 20 de dezembro de 1996.

BRASIL. Parecer 16/1999. Diretrizes Curriculares Nacionais para a Educação Profissional de Nível Técnico.

BRASIL. Parâmetros Curriculares Nacionais: Educação física Secretaria de Educação Fundamental. Brasília: MEC/SEF 1997.

BRASIL. Decreto no 5.478, de 24 de junho 2005 (Revogado). Institui, no âmbito das instituições federais de educação tecnológica, o Programa de Integração da Educação Profissional ao Ensino Médio na Modalidade de Educação de Jovens e Adultos - PROEJA. Diário Oficial da União. Poder

Executivo. Brasília, DF, 27 de junho de 2005.

BRASIL. Decreto $\mathbf{n}^{0}$ 5.840, de 13 de julho 2006. Institui, no âmbito federal, o Programa Revista Labor Fortaleza/CE, jan/jul 2017 Vol. 01, nº 17, p. 13-26 ISSN 1983-5000 
Nacional de Integração da Educação Profissional com a Educação Básica na Modalidade de Educação de Jovens e Adultos - PROEJA, e dá outras providências. Diário Oficial da União. Poder Executivo. Brasília, DF, 14 de julho de 2006.

BRASIL. MEC. Conselho Nacional de Educação. Diretrizes Operacionais para a Educação Básica nas Escolas do Campo. Brasília, dez. 2013.

BRASIL, MEC. Resolução No 2 do CNE/CEB. Estabelece diretrizes complementares, normas e princípios para o desenvolvimento de políticas públicas de atendimento da Educação Básica do Campo. Brasília, abril de 2008.

BOIAGO, D. L.; OLIVEIRA, C. M. Bases legais para uma educação do e no campo e as experiências educativas de uma escola de agroecologia na região norte do Paraná. IX ANPED SUL - Seminário de Pesquisa em Educação na Região Sul. Caxias do Sul. Universidade de Caxias do Sul, 2012.

CIAVATTA, M. A formação integrada: a escola e o trabalho como lugares de memória e de identidade. In: FRIGOTTO, Gaudêncio; CIAVATTA, Maria; RAMOS, Marise (Orgs.). Ensino médio integrado: concepção e contradições. São Paulo: Cortez, 2005.

DARIDO, S.C. Os conteúdos da Educação Física escolar: influências, tendências dificuldades e possibilidades. In: Perspectivas da Educação Física escolar. UFF, v.2, n.1, p. 5- 25, 2001.

DE MARCO, A. Educação Física ou Educação Motora? In: Pensando a Educação Motora. Campinas: Papirus, 1995. p. 27-35.

FONSECA, J. J. S. Metodologia da pesquisa científica. Fortaleza: UEC, 2002.

GARFINKEL, H. Studios en Etnometodología. Barcelona: Anthropos, 2006.

GERHARDT, T; SILVEIRA, D. T. (Org.). Métodos de pesquisa. Porto Alegre: Ed. da UFRGS, 2009. (Série Educação a Distância).

RORAIMA. Ministério da Educação. Universidade Federal de Roraima - UFRR. Conselho de Ensino, Pesquisa e Extensão -CEPE. Resolução 006/2008 - Regimento Interno da Escola Agrotécnica - EAGRO/UFRR. Boa Vista - RR, 2008.

SILVA, T. T. Documentos de Identidade: uma introdução às teorias do currículo. Porto Alegre: Artmed, 2003.

SOUZA FILHO, M. S. A Educação Física e o processo de inclusão dos alunos do PROEJA no IFRN - Uma experiência pedagógica no campus Zona Norte de Natal RN, 2009 In GUIMARÃES, Cristina; VALDEZ, Guiomar (Org.). Dialogando PROEJA: algumas contribuições. Campos dos Goytacazes (RJ): Essentia Editora, 2009.

TOURAINE, A. Poderemos viver juntos? Iguais e Diferentes. Petrópolis: Vozes, 1999.

VEIGA NETO, A. De Geometrias, Currículo e Diferenças IN: Educação e Sociedade, Dossiê Diferenças-2002. 